\title{
Bioterrorismo: apuntes para una agenda de lo inesperado
}

\author{
Samuel Ponce de León-Rosales, MC, M en $C_{\text {, }}^{(1)}$ Eduardo Lazcano-Ponce, Dr en $C_{,}^{(2)}$ \\ Manuel Sigfrido Rangel-Frausto, M en C, MSP, ${ }^{(1)}$ Luis Antonio Sosa-Lozano, MC, ${ }^{(1)}$ \\ Martha Asunción Huerta-jiménez, Lic en Enf. ${ }^{(1)}$
}

\section{Ponce de León-Rosales S, Lazcano-Ponce E, Rangel-Frausto MS, Sosa-Lozano LA, Huerta-Jiménez MA. Bioterrorismo: apuntes para una agenda de lo inesperado. Salud Publica Mex 2001;43:589-603. El texto completo en inglés de este artículo está disponible en: http://www.insp.mx/salud/index.html}

\section{Resumen}

La vulnerabilidad de las poblaciones humanas a terrorismo químico, bioló gico, radiológico y nuclear ha sido ampliamente discutida pero insuficientemente analizada. Las políticas de salud pública carecen de información sólida y relevante para diseñar programas costo-efectivos para prevenir o mitigar este tipo de incidentes en el futuro. Los gobiernos tienen insuficiencia presupuestal para hacer frente a este tipo de ataques. Por lo anterior, en países en desarrollo, como México, es conveniente reflexionar sobre las acciones preventivas particulares, los agentes potenciales y la prevención de la transmisión. Propuestas. La respuesta internacional ante un ataque biológico debe basarse en acuerdos internacionales que prohiben el uso de agentes biológicos con fines de guerra o defensa; así como intercambio académico y tecnológico para la prevención de ataques bioterroristas. Las recomendaciones, a escala nacional, ante un ataque biológico son:a) una estrategia legal de defensa contra bioterrorismo; b) educación, como clave para defensa contra bioterrorismo;c) creación de un programa nacional de coordinación interinstitucional antibioter rorista, que incluya asistencia de urgencias médicas y la obtención de evidencia médica forense; d) instalación de un sistema de vigilancia epidemiológica ante el uso de armas biológicas; e) instauración de un laboratorio de análisis de material biológico

\author{
Ponce de León-Rosales S, Lazcano-Ponce E, \\ Rangel-Frausto MS, Sosa-Lozano LA, Huerta-Jiménez MA. \\ Preparedness against bioterrorist \\ attacks in Mexico. \\ Salud Publica Mex 2001;43:589-603. \\ The English version of this paper \\ is available at: http://www.insp.mx/salud/index.html
}

\section{A bstract}

The vulnerability of human populations to chemical, biological, radiological, and nuclear terrorism has been widely discussed but insufficiently studied. Current public health policies are not guided by solid and relevant information to design cost-effective programs for preventing or controlling this kind of incidents in the future. Governmental budgets are insufficient to respond to bioterrorist attacks. To face these threats, developing countries like Mexico should frame strategies and devise specific preventive actions that consider the transmission dynamics of potential infectious agents likely to be used in a bioterrorist attack. Proposals. The international reaction to a biological attack must be supported by international agreements that ban the use of biological agents for warfare and/or defense purposes, as well as on academic and technological exchange for the prevention of bioter ro rist attacks. At the national level, the recommendations in the event of a biological attack are: a) establishing a legal defense strategy against bioter ro rism; $b$ ) implementing education programs as a key strategy for defense against bioterrorism; c) devising a national program of interinstitutional antibioterrorist coordination that includes medical emergency assistance and collection of medical forensic evidence; d) including a biological weapon registry in epidemiological surveillance systems; e) imple-

(1) Subdirección de Epidemiología Hospitalaria del Instituto Nacional de Ciencias Médicas y N utrición Salvador Zubirán. México, D.F., México.

(2) Centro de Investigación en Salud Poblacional. Instituto N acional de Salud Pública. Cuernavaca, Morelos, México.

Fecha de recibido: 4 de diciembre de 2001 - Fecha de aprobado: 4 de diciembre de 2001

Solicitud de sobretiros: Dr. Samuel Ponce de León Rosales. Subdirección de Epidemiología Hospitalaria del Instituto N acional de Ciencias Médicas y N utrición Salvador Zubirán.Vasco de Q uiroga 15,Tlalpan 14000. México, D.F. Correo electrónico: sponce@ quetzal.innsz.mx

Dr. Eduardo Lazcano-Ponce. Instituto N acional de Salud Pública.Avenida U niversidad 655, colonia Sta. María A huacatitlán. 62508 Cuernavaca, Morelos, México. Correo electrónico: elazcano@ correo.insp.mx 
aso ciado con incidentes terroristas; f) preparación de campañas públicas de información; g) garantía de abasto de material diagnóstico, protección especial y tratamiento de urgencias ante ataques biológicos; $h$ ) descentralización de sistemas de alerta para detección oportuna de terrorismo bioló gico; i) respuesta a acciones bioterroristas dirigidas contra animales y plantas, y j) creación de Comités de Etica ante situaciones de urgencia por un ataque biológico. Conclusiones. El cambiante panorama epidemiológico requiere de una infraestructura suficiente para establecer diagnósticos de enfermedades emergentes o insólitas como sería el caso de una agresión bioterrorista. La tecnología permite ahora identificar, en pocas horas, a múltiples agentes infecciosos por análisis de ácidos nucleicos y debería ser accesible en laboratorios de referencia. To das las acciones requieren de presupuestos suficientes para enfrentar esta posible eventualidad. La situación es potencialmente de extrema gravedad y así deberá considerarse al cuantificar la inversión. El texto completo en inglés de este artículo está disponible en: http://www.insp.mx/salud/index.html

Palabras clave: bioterrorismo; agentes para guerra biológica; respuesta institucional; México menting a laboratory for biological material analysis related to terrorist incidents; f) devising public health information campaigns, g) assuring the supply of diagnostic testing, special protection, and emergency treatment materials; $h$ ) decentralizing alert systems for the timely detection of bioterrorist attacks; i) responding to bioterrorist actions addressed against animals and plants, and j) organizing Ethics Committees in case of urgent events derived from a biological attack. Conclusions. The proper response to sudden and unexpected events of emergent or unusual infectious diseases involved in a bioterrorist attack requires an adequate public health infrastructure. Modern technology allows the timely identification of multiple infectious agents by nucleic acid analyses and should be widely available in reference laboratories.All these measures require sufficient funding to respond to this potential threat. Resource allocation to respond to bioterrorist attacks must be consonant with their potential public health consequences. The English version of this paper is available at: http:// www.insp.mx/salud/index.html

Key words: bioterrorism; biological warfare agents; institutional response; Mexico
$P$ ocos días después de los acontecimientos del 11 de septiembre de 2001, a inicios de octubre, el panorama de la medicina se enfrenta con un nuevo escenario: la amenaza del uso de agentes biológicos con propósitos criminales, que hoy se presenta en un contexto de terrorismo, haciendo ciertos los pronósticos que desde hace varios años indicaban la inminencia de este tipo de agresiones. La distribución del carbunco (ántrax) por correo, hasta ahora ha afectado a 10 pacientes en los Estados Unidos de América (EUA) entre el 4 de octubre y el 2 de noviembre de 2001, y ha causado una extraordinaria movilización de los sistemas de protección social y de recursos para la salud, no sólo en EUA sino en todo el mundo. Este es el primer aviso de una insólita situación..$^{1,2}$

Este número de casos puede interpretarse como resultado de una respuesta institucional muy deficiente puesto que en realidad son muy pocos los enfermos. Pero considerada la respuesta de los medios de comunicación y el miedo del público, el ataque ha sido muy exitoso, puesto que moviliza a grandes sectores a realizar intervenciones y es motivo de miedo, pánico e histeria en grandes sectores, insistimos, no sólo de EUA sino del mundo.

El uso de agentes infecciosos usados intencionalmente no es nuevo en las actividades militares. Uno de los primeros antecedentes son los efectuados en el siglo XIV por los tártaros para romper el sitio de Kaffa (Feodossia) catapultando los cuerpos de sus soldados, infectados de peste bubónica, sobre los muros de la ciudad. Con este hecho, acaecido entre 1348 y 1350, posiblemente se inició la mayor epidemia de peste negra en el ámbito mundial, estimándose que causó la muerte de $30 \%$ de la población europea. En nuestro continente sabemos del caso de la distribución de cobijas de enfermos con viruela a los indígenas norteamericanos por el ejército americano, o la contaminación intencional con cólera del río Mississippi durante la guerra civil, y como ejemplo de la eficacia de los agentes infecciosos tenemos las epidemias de sarampión y viruela que asolaron a la población mexicana en la guerra de la conquista, y que para algunos autores fueron la explicación de la eficiencia militar de los conquistadores. ${ }^{3}$ Recientemente, dos circunstancias han sido motivo de preocupación para los estrategas militares, uno fue el accidente de una planta de Biopreparat en Sverdlovsk, ciudad de la entonces Unión de Repúblicas Socialistas Soviéticas (URSS), en donde un accidente de ventilación permitió el escape de esporas de Bacillus anthracis hacia los alrededores ocasionando 69 muertes. La publicación de informes conservados subrepticiamente, por médicos que ahí trabajaron, permitió conocer los datos epidemiológicos más importantes. ${ }^{4}$ Más recientemente, el conflicto entre EUA e Irak reveló la existencia de plantas productoras de agentes biológicos infecciosos para ser usados como armas dispersables inclusive en misiles, lo que hipotéticamente podría resultar en una catás- 
trofe, no sólo para los países en conflicto sino para la humanidad. ${ }^{5}$ Imagine el lector un ataque con el virus de viruela que vendría a echar abajo el esfuerzo que globalmente se hizo para erradicarla y que, en magnitud, podría equipararse a un ataque nuclear masivo con la agravante de que la viruela persistiría extendiéndose hacia todo el planeta.

Además, el actual desarrollo biotecnológico permite imaginar escenarios escalofriantes ante la potencial creación de organismos que combinen alta transmisibilidad, elevada mortalidad y ausencia de tratamientos eficientes. Esta es una realidad con la que tendremos que vivir de ahora en adelante y que ejemplifica una vez más los riesgos del desarrollo tecnológico en situación de desequilibrio social.

Otra situación a considerar es la posibilidad de producir "en casa" algunos de estos agentes en tanto la tecnología para hacerlo es accesible, y la única limitación es el conocimiento técnico. ${ }^{6}$

La distribución de esporas de Bacillus anthracis por el correo norteamericano hace real una situación muy grave y confirma la preocupación constante mantenida desde hace casi una década. Cada vez que revisemos un enfermo con una infección inusual o de diagnóstico difícil, o que semeje alguna de las entidades identificadas en asociación con terrorismo se tendrá que considerar la posibilidad de estos diagnósticos y, en consecuencia, de bioterrorismo.

Ante lo insólito de la situación, los autores intentamos exponer esquemáticamente información que invite a la reflexión y a la instalación de sistemas que nos permitan una temprana identificación, en el caso de que esta remota posibilidad se concrete.

La vulnerabilidad de las poblaciones humanas a terrorismo químico, biológico, radiológico y nuclear ha sido ampliamente discutida pero insuficientemente analizada. Las políticas de salud pública carecen de información sólida y relevante para diseñar programas costo-efectivos para prevenir o mitigar este tipo de incidentes en el futuro. ${ }^{3}$ Los gobiernos tienen insuficiencia presupuestal para hacer frente a este tipo de ataques; modelos matemáticos han evaluado el impacto económico de un ataque bioterrorista con viruela en la frontera México-EUA, prediciendo una estimación de costos de $\$ 26.2$ billones de dólares por 100000 personas expuestas. $^{7}$

Por lo anterior, es conveniente reflexionar sobre las acciones preventivas particulares, los agentes potenciales y la prevención de la transmisión.

\section{Acciones institucionales}

En el cuadro I se muestran las principales acciones institucionales que se deben diseñar como respuesta de los sistemas de salud ante un ataque biológico. Sin embargo, en países desarrollados existe actualmente controversia en establecer si estos eventos podrían ser cuantificados con algún tipo de precisión, y caracterizados los agentes biológicos utilizados. Asimismo, sería difícil disponer de información sobre la escala del ataque y la magnitud de los efectos. Particularmente, se debate si existe una infraestructura disponible para ofrecer una respuesta efectiva, y si las acciones propuestas, o actualmente en planeación, serían proporcionales al daño causado. Adicionalmente, no se han establecido criterios de eficacia, seguridad y reservas financieras para dar respuesta a los elevados costos de prevención y atención médica. ${ }^{8,9}$

\section{Medidas internacionales}

Las leyes básicas internacionales prohiben el uso de agentes biológicos en los conflictos armados y el primer antecedente lo registra, en 1925, el Protocolo de Ginebra. ${ }^{1}$ Posteriormente, en 1969, La Asamblea General de las Naciones Unidas emitió una resolución que hace recomendaciones a dicho Protocolo. Adicionalmente,

\section{Cuadro I \\ Acciones institucionales de Los Sistemas DE SALUD ANTE UN ATAQUE BIOLÓGICO}

Respuesta internacional

a) Acuerdos internacionales que prohiben el uso de agentes biológicos con fines de guerra o defensa

b) Intercambio académico y tecnológico

Recomendaciones a nivel nacional

1) $\mathrm{N}$ ecesidad de una estrategia legal de defensa contra bioterrorismo

2) Educación es la clave para defensa contra bioterrorismo a) pregrado; b) especialización; c) educación médica continua

3) Creación de un programa nacional de coordinación interinstitucional antibioterrorista, que incluya asistencia de urgencias médicas y la obtención de evidencia médica forense

4) Instalación de un sistema de vigilancia epidemio lógica ante el uso de armas biológicas

a) Evidencias epidemiológicas

b) Reconocimiento y notificación del evento

- Definición de caso

- Evaluación de curvas epidémicas

c) Cerco epidemiológico

5) Instauración de un laboratorio de análisis de material biológico asociado con incidentes terroristas

6) Preparación de campañas públicas de información

7) Garantía de abasto de material diagnóstico, protección especial y tratamientos de urgencias ante ataques biológicos

8) Descentralización de sistemas de alerta para detección oportuna de terrorismo biológico

9) Respuesta a acciones bioterroristas dirigidas contra animales y plantas

10) Creación de Comités de Etica ante situaciones de urgencia por un ataque biológico 
se desarrolló la Convención Mundial de Armas Biológicas y Toxinas en 1972, que fue revisada en 1975, 1980, 1986, 1991 y 1996. Esta convención está en contra del desarrollo, producción, adquisición y acúmulo de microrganismos y sus productos, excepto para fines pacíficos.

\section{Recomendaciones en el ámbito nacional ante un posible ataque bioterrorista}

Las recomendaciones generales en el ámbito nacional para dar respuesta a una sospecha de un evento bioterrorista se describen a continuación:

\section{Necesidad de una estrategia legal de defensa contra} bioterrorismo

El bioterrorismo es causa de urgencia en la salud pública, por lo que constituye un estado de excepción, donde se pueden abandonar principios elementales de la legislación por conveniencia. La implementación de cambios no sólo deberá ser en las leyes, sino también en los valores sociales y normas, así como en la imparcialidad y equidad; necesarias para que los tomadores de decisiones distribuyan adecuadamente los escasos recursos ante la presencia de un ataque biológico. ${ }^{11}$

\section{Educación es la clave para la defensa contra el bioterrorismo}

Las enfermedades que potencialmente los servicios de salud deben enfrentar no son parte de la práctica diaria, y eventualmente son condiciones que muchos de nosotros conocimos teóricamente en las escuelas de medicina. Por esta razón, en primera instancia se deben adiestrar profesionales de urgencias médicas, preparados para establecer estrategias de defensa contra la posibilidad de víctimas masivas, pánico, así como trastornos producidos por carbunco (ántrax), peste bubónica, viruela, tularemia, entre otros. ${ }^{12}$ Estos profesionales deberán tener la capacidad no sólo de identificar cambios en los patrones epidemiológicos, sino de establecer y coordinar los sistemas de vigilancia epidemiológica creados para minimizar y controlar la elevada morbilidad y mortalidad que se puede provocar. Adicionalmente, la organización de programas de entrenamiento continuo altamente especializado para ataques bioterroristas, dirigidos no sólo al personal de urgencias, sino a profesionales de la salud de los tres niveles de atención médica, se constituye como una necesidad impostergable. El entrenamiento debe incluir principios epidemiológicos básicos, tales como información clínica sobre diagnóstico y tratamiento de los agentes que pueden ser la más alta amenaza, así como el aislamiento de sujetos y material que ha sido expuesto. ${ }^{13}$ Los programas de educación deberán ser continuos para mantener la vigencia de los conocimientos y las acciones permanentes a desarrollar.

Creación de un programa nacional de coordinación interinstitucional anti-bioterrorista, que incluya asistencia de urgencias médicas y obtención de evidencia médica forense

Una respuesta efectiva nacional a los incidentes químicos o biológicos será resultado de la capacidad federal para coordinar, capacitar y subsidiar todas las acciones, donde las líneas prestablecidas de comunicación y mando son un elemento crítico. ${ }^{14}$ Todas las acciones deberán considerar los principios de la salud pública, en ese sentido, una respuesta inapropiada por la comunidad médica puede empeorar una situación caótica y devastadora.

En México se ha creado la Comisión Interinstitucional para la Protección de la Salud ante el Uso de Armas Biológicas, cuyo principal objetivo es reforzar la vigilancia epidemiológica, mejorar el diagnóstico y la atención oportuna, así como fortalecer los sistemas de información y coordinación. Esta Comisión Interinstitucional está constituida por un grupo de trabajo formado por la Secretaría de Salud, la Secretaría de Gobernación -incluyendo la Dirección de Protección Civil y Centro de Inteligencia de Seguridad Nacional-, la Secretaría de Comunicaciones y Transportes -a través del Servicio Postal Mexicano-, la Secretaría de Seguridad y Protección -mediante la Policía Federal Preventiva-, la Secretaría del Medio Ambiente y Recursos Naturales, la Procuraduría General de la República, el Sistema Nacional de Salud en su conjunto, la Universidad Nacional Autónoma de México y el Instituto Politécnico Nacional.

\section{Instalación de un sistema de vigilancia epidemiológica} ante el uso de armas biológicas

Los agentes biológicos y químicos son diferentes en diversas maneras. Desde el punto de vista de la salud pública este hecho es muy importante, porque los efectos de agentes químicos usualmente son inmediatos, mientras que los agentes biológicos tienen un período de incubación y producen efectos en horas o comúnmente días después de la exposición. Muchos agentes químicos son volátiles y producen un vapor peligroso, mientras que los agentes biológicos no lo son y no producen este tipo de daño. Los agentes biológicos de hecho requieren energía a través del aire en movi- 
miento. Muchos de los agentes químicos pueden producir efectos fisiopatológicos por penetración de piel intacta; los agentes biológicos, con la posible excepción de las T-2 micotoxinas, no producen efecto alguno cuando llegan a estar en contacto con un tegumento intacto, a diferencia de un ataque químico donde la respuesta es inmediata y debe apoyarse en policías, bomberos y adicionalmente, en personal médico y paramédico, en un ataque biológico la respuesta inmediata debe ser ofrecida por los servicios de salud.

Se deberán establecer todas las fases de un programa de vigilancia epidemiológica, incluidas las visitas a salas de urgencias, uso de datos de laboratorio, disponibilidad de tratamiento médico, monitoreo de ausentismo escolar y laboral, y algunos otros datos que nos permitan sospechar del incremento de una enfermedad infecciosa. Asimismo, son esenciales los sistemas de vigilancia epidemiológica robustos para detectar algunas enfermedades emergentes o remergentes, pues el rápido reconocimiento de algún cambio en el patrón de enfermedad facilitará la determinación de la fuente y prevención de la nueva exposición. Al respecto, en México se ha reforzado el sistema de vigilancia epidemiológica mediante una red de 133 unidades de salud "centinelas". Desgraciadamente, los sistemas actuales de vigilancia epidemiológica para detectar agentes infecciosos emergentes no son adecuados para identificar potenciales agentes bioterroristas. ${ }^{15}$

El abordaje epidemiológico en la evaluación de un potencial ataque bioterrorista no difiere de la investigación epidemiológica estándar. El primer problema que se puede presentar es la falta de coordinación de oficinas gubernamentales y dificultad para hacer frente a un número significativo de posibles muertes. Afortunadamente, la probabilidad de un ataque biológico o químico para la República mexicana es extremadamente baja. En este contexto, sin embargo, deben implementarse acciones comunitarias para enfrentar este gran reto, entre las que se incluyen:

\section{a) Evidencias epidemiológicas}

Las evidencias descritas en el cuadro II pueden ayudar a determinar la posibilidad de un ataque bioterrorista. Cuando estamos en presencia de más de uno de estos indicadores podemos sospechar la presencia de un ataque intencional, y el sistema de vigilancia epidemiológica debe ponerse en alerta.

\section{b) Reconocimiento y notificación del evento}

Cada servicio de salud deberá contar con una lista de números telefónicos para notificación de un posible

\section{Cuadro II \\ EvidenCIAS EPIDEMIOLÓGICAS QUE DETERMINAN LA POSIBILIDAD DE UN ATAQUE BIOTERRORISTA}

1. Un rápido incremento de la incidencia de enfermedad en una población normalmente saludable

2. Una curva epidémica que se eleva y cae bruscamente en un corto período de tiempo

3. Un inusual incremento en el número de personas que utilizan servicios de salud, especialmente con fiebre y síntomas respiratorios ó gastrointestinales

4. Enfermedad más severa que la esperada para un patógeno dado

5. Una inusual ruta de exposición y atípia clínica en la presentación de enfermedad

6. Una enfermedad endémica que rápidamente progresa, que es inusual para un área geográfica dada, fuera del proceso de transmisión normal, o imposible de transmitirse naturalmente en ausencia de un vector de transmisión

7. Múltiples epidemias simultáneas de diferentes enfermedades

8. U na enfermedad de origen zoonótico con consecuencias humanas

9. Cepas inusuales o variantes de organismos o patrones de resistencia antimicrobiana dispares para aquellos circulantes

10. Bajas tasas de ataque en personas que han estado en lugares cerrados, en comparación con los que han estado expuestos al ambiente externo

11. Grupos grandes de pacientes que acuden a servicios de salud de una simple localidad

12. Gran número de casos que fallecen rápidamente

13. Reporte de enfermedad 0 muerte en gran número de animales 0 plantas

14. Conocimiento del acceso a un agente o agentes de un grupo terrorista

15. Reivindicación de un grupo terrorista, de la liberación de un agente biológico

16. Evidencia directa de la diseminación de un agente biológico como consecuencia de un ataque bioterrorista

evento bioterrorista y un plan de acción preparado. La rápida respuesta a un ataque bioterrorista depende de la identificación del evento, porque la rápida progresión a enfermedad y potencial diseminación de algunos de estos agentes no hacen práctico esperar la confirmación del laboratorio. Así, el reconocimiento de síndromes de alto riesgo es imperativo, por lo que se deben realizar las siguientes acciones epidemiológicas:

Definición de caso

El primer paso es usar el laboratorio y los hallazgos clínicos para confirmar que la enfermedad ha ocurrido. La definición de caso debe establecerse para determinar el número de casos y la tasa de ataque. El uso de criterios objetivos en el desarrollo de una definición de caso es muy importante para estimar el número exacto de casos, ya que el número de éstos puede incrementarse y algunos otros pueden ser descartados, especialmente los producidos por confusión e histeria con la actual enfermedad. 
Una vez que la definición de caso y la tasa de ataque han sido determinadas, el evento resultado puede ser caracterizado en su convencional contexto de tiempo, lugar y persona. Esta información será crucial para determinar la fuente potencial de exposición.

\section{Evaluación de curvas epidémicas}

Usando los datos obtenidos en un tiempo determinado, se deberá construir una curva epidémica. El patrón de enfermedad es un factor importante para diferenciar entre un brote natural y un ataque intencional. En la mayoría de las epidemias que ocurren naturalmente, el número de casos se incrementa progresiva y gradualmente de acuerdo con el número de personas que han estado en contacto con otros pacientes, fomites y vectores que pueden diseminar la enfermedad. Contrariamente, un ataque bioterrorista será causado por una fuente puntual, donde los individuos llegarán a estar en contacto con el agente aproximadamente al mismo tiempo; en este caso, la curva epidémica estará comprimida, con un pico de sólo unas cuantas horas o días y sin que existan muchas diferencias en las manifestaciones clínicas y periodos de exposición; si el agente biológico es contagioso, es posible observar un segundo pico después del primero, derivado de la exposición al agente de personas no expuestas originalmente.

El exceso esperado en la curva epidémica en un ataque bioterrorista es similar al que puede observarse con otras exposiciones de fuente puntual, tales como las de origen alimenticio.

Si un grupo específico ha sido expuesto, la curva epidémica puede indicar el tiempo de exposición. Con esta información se puede calcular un posible periodo de incubación, esto ayuda a determinar la causa potencial de enfermedad, que puede ser sugestiva de un ataque intencional si el periodo de incubación es más corto que el usual.

Calcular el periodo de incubación puede ayudar a determinar si la enfermedad se disemina de persona a persona, lo que es extremadamente importante para establecer medidas efectivas de control de enfermedad..$^{16}$

\section{c) Cerco epidemiológico}

Tradicionalmente, en los brotes epidémicos se ha utilizado como una herramienta de campo la construcción de cercos epidemiológicos para facilitar el trabajo de identificación de casos y delimitar la epidemia. En presencia de epidemias asociadas a bioterrorismo, es necesario realizar actividades que delimiten rápidamente la posible expansión del cuadro, identificar el agente, y proteger de la exposición a poblaciones cercanas a la fuente de infección, todo ello de forma inmediata y coordinada entre los servicios de protección civil.

Instauración de un laboratorio de análisis de material biológico asociado con incidentes terroristas

Los laboratorios clínicos deberán estar preparados para proveer un diagnóstico rápido, oportuno y altamente sensible, necesario para diseñar estrategias de tratamiento. ${ }^{17} \mathrm{Al}$ respecto, en EUA los criterios que se han establecido para laboratorios clínicos que deben procesar agentes de posible origen bioterrorista son:

Nivel A: con capacidad para identificación mínima de agentes

Nivel B: cuentan con pruebas para identificación y confirmación de agentes

Nivel C: laboratorios con capacidad avanzada para diagnóstico, incluyendo tecnologías moleculares

Nivel D: aquellos laboratorios con gran capacidad y técnicas avanzadas de tipificación molecular.

Por esta razón, en los países, se deben de caracterizar los laboratorios clínicos de acuerdo a esta clasificación. En la República mexicana, la SSA cuenta con siete laboratorios regionales para el diagnóstico oportuno en Chihuahua, Jalisco, Nuevo León, San Luis Potosí, Sonora, Quintana Roo y Veracruz, bajo la coordinación del Instituto de Diagnóstico y Referencia Epidemiológica y el Laboratorio Nacional de Salud Pública.

\section{Preparación de campañas públicas de información}

Una adecuada estrategia de comunicación pública es importante para minimizar la propagación de agentes infecciosos y evitar confusión. A este respecto, es importante prevenir que el pánico se apodere de la población y organizar el desalojo para evitar caos en el área afectada. En este contexto, los servicios públicos de salud deben difundir anuncios por radio y televisión posterior al ataque biológico, informando a la población general acerca de la naturaleza del ataque, los síntomas que pueden generarse, y cómo ellos pueden minimizar la exposición, así como posibilidades de tratamiento.

En México, la SSA ha establecido un número de información telefónica en la Ciudad de México (01-800- 
00-44-800) donde la población puede solicitar información de exposición ante agentes biológicos de origen posiblemente terrorista.

Garantía de abasto de material diagnóstico, protección especial y tratamiento de urgencia ante ataques biológicos

Es indispensable el establecimiento de una infraestructura de equipo médico, abasto de antídotos, antibióticos de amplio espectro, drogas antivirales y vacunas, en las principales áreas metropolitanas. Este programa en particular será muy costoso, porque se requerirá de equipo especializado, suplementos y elevados estándares de sofisticación.

Descentralización de sistemas de alerta para detección oportuna de terrorismo biológico

Se requiere instalar, en el ámbito nacional, mecanismos de descentralización temprana de sistemas de alerta para la detección oportuna de ataques bioterroristas. La elaboración de un plan nacional contra un ataque bioterrorista es fundamental, y el sistema de vigilancia epidemiológica debe incluir las instituciones del sistema nacional de salud en el ámbito municipal y estatal, instituciones de salud privadas, organizaciones civiles y gubernamentales, particularmente de protección civil.

Respuesta a acciones bioterroristas dirigidas contra animales y plantas

Existe una necesidad de respuesta inmediata a enfermedades como influenza en aves, encefalomielitis equina venezolana y la enfermedad de Newcastle; la desplegada en estas últimas ha sido ampliamente reconocida por las estrategias comunitarias globales de urgencia, y ha dado lugar a modelos de erradicación y control. $^{18}$

Creación de Comités de Etica ante situaciones de urgencia por un ataque biológico

Los posibles ataques bioterroristas deberán tener un efecto sobre muchos sectores de la sociedad, pero particularmente sobre la provisión de los servicios de salud. Se encontrarán situaciones en que la demanda de los recursos claramente excederá la infraestructura y suplemento de los mismos; por esta razón, los proveedores y administradores de los servicios médicos, junto con organizaciones gubernamentales y civiles, necesitarán abordar este posible hecho y tomar decisiones para establecer prioridades en la distribución de los recursos ante la manifestación de un ataque bioterrorista. ${ }^{19}$

\section{Principales microrganismos que se pueden utilizar con fines bioterroristas}

Para que un microrganismo pueda ser utilizado con estos propósitos debe cumplir con estas características: ser fácil de manipular en laboratorio, tener bajos costos de producción, poder sobrevivir durante largo tiempo bajo condiciones adversas y diseminarse en forma de aerosoles o a través de alimentos. ${ }^{6,20,21}$ En el cuadro III se muestran agentes que cumplen estos requisitos independientemente del mecanismo natural de transmisión.

\section{Carbunco (ántrax)}

Es la enfermedad producida por Bacillus anthracis, bacilo gram positivo esporulado causante de infección en herbívoros y que accidentalmente produce enfermedad en el hombre. El microrganismo puede permanecer en la naturaleza en forma de esporas que son muy resistentes por largos periodos de tiempo. Debido a sus características como son: alta potencia, fácil accesibilidad y relativa fácil contaminación, podría utilizarse como arma biológica. Una millonésima de un gramo es la dosis letal. Un kilogramo, dependiendo de las condiciones del ambiente, tiene el potencial de matar cientos de miles de personas en un área metropolitana.

En casos naturales, más de $95 \%$ de los casos son cutáneos y $5 \%$ respiratorios. El periodo de incubación va de 1 a 60 días. El carbunco cutáneo es muy característico, se presenta principalmente en manos y brazos, seguido de la cara y el cuello. Consiste en una pápula que da mucha comezón, semejando una picadura por un insecto, ésta crece en los siguientes 1 a 2

\section{Cuadro III \\ Principales microrganismos Y LAS ENFERMEDADES QUE PROVOCAN}

Bacillus anthracis

Yersinia pestis

Fracisella tularensis

Brucella sp

Coxiella burnetii

Alfa virus

Virus de las fiebres hemorrágicas Viruela virus

Clostridium botulinum

Fuente: referencias 21 y 22
Antrax o Carbunco

Peste

Tularemia

Brucelosis

Fiebre Q

Encefalitis equina venezolana

Encefalitis equina del este y del oeste

Fiebres hemorrágicas

Viruela

Botulismo 
días y se convierte en una úlcera rodeada de vesículas, la lesión es de 1 a $3 \mathrm{~cm}$ de diámetro, redonda y regular, se produce una cicatrización central de color negro. Después de 1 a 2 semanas la lesión empieza a secar y la cicatriz se cae, no es raro que existan crecimientos de los ganglios regionales.

La forma respiratoria es secundaria a la germinación de la espora al ser transportada por macrófagos a los ganglios hiliares y mediastinales, donde producen hemorragia e inflamación muy importantes; ésta se extiende hacia la pleura produciendo derrame. Los síntomas se inician con manifestaciones generales que duran de 1 a 3 días y que se caracterizan por mal estado general, fiebre moderada, tos seca y en ocasiones la sensación de opresión subesternal, seguidas de una fase de inicio súbito acompañada de choque séptico en 1 a 2 días. Los síntomas predominantes en esta fase son disnea en reposo, estridor, tos seca, taquicardia, fiebre elevada, sudoración profusa, en ocasiones acompañada de sangrado del tubo digestivo. Aproximadamente $20 \%$ del ántrax cutáneo puede ser mortal, mientras que la forma respiratoria casi siempre lo es.

En los 10 casos confirmados de carbunco (ántrax) por inhalación que se han presentado en EUA, el periodo de incubación tuvo un promedio de cuatro días, los síntomas iniciales fueron fiebre, escalofríos, diaforesis, fatiga, tos no productiva, disnea, nausea y vómito. Todos presentaron anormalidades en la radiografía de tórax de las cuales siete tuvieron ensanchamiento mediastinal. El 60\% sobrevivieron con antibióticos. ${ }^{1}$

En cuanto al tratamiento para carbunco por inhalación, el Center for Disease Control and Prevention (CDC) recomienda utilizar de primera elección ciprofloxacina $400 \mathrm{mg} / \mathrm{IV} \mathrm{c} / 12 \mathrm{~h}$ o doxiciclina $100 \mathrm{mg} /$ IV c/12 h y posteriormente se cambia a vía oral. Anteriormente el agente de primera línea para carbunco por inhalación era penicilina, sin embargo, en las cepas recientemente aisladas de los ataques bioterroristas ocurridos en EUA se ha encontrado actividad $\beta$-lactamasa. En caso de sospecha de carbunco, como resultado de bioterrorismo o por exposición, se recomienda profilaxis con ciprofloxacina $500 \mathrm{mg}$ dos veces al día o doxiciclina $100 \mathrm{mg} \mathrm{c} / 12 \mathrm{~h}$, por lo menos durante seis semanas.

Los apósitos de las lesiones deben ser incinerados, esterilizados por autoclave, asimismo los pacientes con lesiones cutáneas deben ser puestos en aislamiento de contacto. No se ha descrito transmisión persona a persona.

Existe una vacuna de filtrados de cepas avirulentas de una cepa no encapsulada. Tiene una efectividad de $92.5 \%$ y debe utilizarse para todas las personas expuestas a materiales contaminados; la dosis es de $0.5 \mathrm{ml}$ subcutáneos a las 0,2 y 4 semanas y nuevamente a los 6,12 y 18 meses, seguida de una dosis de refuerzo anual. ${ }^{22-24}$

Peste

Es producida por el microrganismo Yersinia pestis, que es un bacilo gram negativo. Se trata de una enfermedad primariamente de animales y es transmitida de los reservorios animales, principalmente roedores, a través de pulgas o la ingestión de tejidos animales contaminados. Los humanos se infectan por la exposición a la pulga; menos frecuentemente, la infección puede transmitirse de persona a persona en la forma neumónica a través de gotitas de Flügge. La transmisión puede ocurrir también durante el manejo de tejidos o líquidos contaminados con el microrganismo.

La forma clásica, o bubónica, ocurre después de un periodo de incubación de 2 a 8 días después de la infección y se caracteriza por el inicio súbito de fiebre, escalofríos, debilidad y cefalea; casi inmediatamente el paciente nota el crecimiento de un ganglio muy doloroso, generalmente en axila, ingle o cuello; estos ganglios pueden ser de $1 \mathrm{a} 10 \mathrm{~cm}$. El paciente desarrolla sepsis grave, $25 \%$ de ellos pueden desarrollar lesiones en la piel que consisten en vesículas, pústulas o pápulas cerca del ganglio o bubón. También puede acompañarse de púrpura.

La forma neumónica es la forma de presentación más probable que se da en caso de un ataque bioterrorista; es producida por la aspiración de gotitas de Flügge o por la invasión hematógena secundaria de los pulmones. Es altamente contagiosa y tiene una muy elevada mortalidad. Después de un periodo de incubación de 2 a 3 días se produce una neumonía que produce lesiones confluentes y en ocasiones cavitadas, se acompaña de tos productiva, en ocasiones hemoptisis, cuyo esputo contiene los bacilos. Esta forma es casi invariablemente fatal a menos que se inicie tratamiento dentro de las 24 horas luego de iniciados los síntomas. El paciente fallece de insuficiencia respiratoria aguda o choque.

El tratamiento consiste en estreptomicina $30 \mathrm{mg} /$ $\mathrm{kg} /$ día divididos en dos dosis por 10 días. Tetraciclinas 2 a $4 \mathrm{~g} /$ día $/ 10$ días es una alternativa adecuada. En pacientes con meningitis puede utilizarse cloranfenicol. Se ha descrito al menos un caso de resistencia a estreptomicina, tetraciclinas y cloranfenicol, pero sensible a trimetoprim-sulfametoxasol.

Todos los pacientesdebenser puestos en aislamiento, $\mathrm{y}$ aquellos con tos, en aislamiento respiratorio. ${ }^{21,22}$ 


\section{Tularemia}

Es producida por un cocobacilo gram negativo llamado Francisella tularensis que produce infección principalmente en animales. Existen reportes del potencial de este microrganismo en una guerra biológica debido a que la tasa de ataque después de una exposición masiva aérea es de $82.5 \%$ y la mortalidad de $6.2 \%$, con costos para los servicios de salud entre 456 y 562 millones de dólares. ${ }^{19,22}$

Esta es una enfermedad principalmente del hemisferio norte que afecta a conejos, ardillas y roedores. La transmisión al humano ocurre generalmente por mordeduras de artrópodos y pulgas o el contacto o ingestión de productos contaminados; aunque es posible la transmisión en aerosoles, no se ha reportado transmisión humano a humano.

Las manifestaciones dependen de la virulencia del microrganismo, la puerta de entrada, y el estado inmunológico del paciente. Las variedades sintomáticas incluyen: ulceroglandular, glandular, oculoglandular, faríngea, tifoídica y neumónica, aunque las manifestaciones con mucha frecuencia son de más de un tipo.

Los síntomas se inician 3 a 5 días después de la exposición. Inicia con cefalea, fiebre, escalofríos, mal estado general, disminución del apetito. Pueden aparecer además tos, dolor en tórax, vómitos, disfagia, dolor abdominal y diarrea. Sin tratamiento la fiebre dura hasta 32 días.

La forma neumónica es posible que sea la más común en caso de una exposición por bioterrorismo, ya que es producida por la inhalación del organismo, aunque también puede ocurrir por la diseminación hematógena al pulmón. Se caracteriza por síntomas respiratorios progresivos que pueden llegar hasta síndrome de insuficiencia respiratoria progresiva del adulto; el esputo no sugiere el diagnóstico; puede acompañarse de derrame pleural. El diagnóstico debe sospecharse ante una neumonía atípica de la comunidad que no responde a tratamiento.

El tratamiento de elección es con estreptomicina, $30 \mathrm{mg} / \mathrm{kg}$ IM en dos dosis por 10 a 14 días. La gentamicina también es efectiva.

Los pacientes hospitalizados no requieren más que precauciones estándar ya que no existe transmisión persona a persona. Se recomienda manejar con precaución drenajes de heridas o exudados oculares. ${ }^{21,22}$

\section{Brucelosis}

Se produce por cocobacilos gramnegativos aerobios no toxigénicos y no formadores de esporas. Existen seis especies de brucela y cada una infecta a diferentes hués- pedes animales en los que usualmente provoca aborto e infertilidad. Solamente cuatro especies son patógenas para el humano, Brucella melitensis, Brucella suis, Brucella abortus y Brucella canis.

El humano se infecta por contacto con tejidos de animales infectados o la ingestión de productos animales contaminados. No se produce transmisión de persona a persona, pero es altamente infectante en aerosol; los EUA procesaron B. suis como arma biológica en los años de las décadas de 1940 y 1950 en la forma de aerosol seco.

Es un parásito de neutrófilos, intracelular, y se localiza dentro de órganos (pulmón, bazo, hígado, sistema nervioso central -SNC-, médula ósea y membranas sinoviales). Los síntomas son similares en pacientes con infección oral, por aerosol o percutánea. Usualmente hay fiebre, escalofríos y malestar. Las manifestaciones respiratorias se presentan en $20 \%$ de los pacientes y se manifiestan por tos seca y dolor pleurítico. Sacroileitis y osteomielitis vertebral son las manifestaciones osteoarticulares más comunes. La endocarditis y afección del SNC son raras pero constituyen las principales causas de mortalidad. Aun sin antibióticos la mayoría de los pacientes se recuperan en un año, pero son comunes las recaídas.

El diagnóstico se hace con pruebas de aglutinación; también los cultivos de sangre, médula ósea y sitios focales de infección pueden resultar positivos.

Se recomienda usar combinación de antibióticos para el tratamiento, ya que la monoterapia tiene pobre respuesta. La combinación de $200 \mathrm{mg} /$ día de doxiciclina oral y 600 a $900 \mathrm{mg}$ de rifampicina oral es el tratamiento de elección. Se puede substituir la rifampicina por trimetropin-sulfametoxasol. ${ }^{20-22}$

\section{Fiebre Q}

Se trata de una enfermedad zoonótica de distribución mundial que resulta de la exposición al ganado. El microrganismo causal es la Coxiella burnetti, es un parásito intracelular obligado, de baja virulencia pero muy infectante, productor de esporas que puede causar infección después de una exposición indirecta con animales infectados.

Actualmente la fiebre $Q$ se reconoce como un agente potencial para bioterrorismo dado que comparte algunas características con el carbunco.

En un gran porcentaje de las personas infectadas la enfermedad puede ser asintomática. El inicio de la sintomatología suele ser insidioso con fiebre, escalofríos, cefalea, diaforesis, malestar, fatiga y anorexia. Frecuentemente hay mialgias. Se presentan erupciones cutáneas pero no se ha descrito un exantema particu- 
lar. Se produce fiebre fluctuante en $25 \%$ de los casos, con picos de $39.4{ }^{\circ} \mathrm{C}$ a $40.6{ }^{\circ} \mathrm{C}$.

Los estertores son un hallazgo común, al igual que derrame pleural y consolidación. Puede haber hepatoesplenomegalia pero no en la fase aguda de la enfermedad. En las pruebas de función hepática es común la elevación de la aspartato aminotransferasa (AST) a 2 o 3 veces el valor normal. El diagnóstico se hace mediante detección de anticuerpos por la prueba ELISA.

El tratamiento acorta la evolución, las tetraciclinas son de primera elección. También los macrólidos, quinolonas, cloranfenicol y trimetoprim-sulfametoxasol son efectivos. ${ }^{21,22}$

\section{Encefalitis virales}

Los virus de la encefalitis venezolana, encefalitis equina del este y del oeste, son alfavirus de la familia Togaviridae. Poseen varias características que los hacen aptos para utilizarse como armas biológicas. Aunque se transmiten por vectores como mosquitos, son altamente infectantes en forma de aerosol. No se requiere de sistemas sofisticados ni de altos costos para producirlos en grandes cantidades. También pueden someterse a manipulación genética mediante modernas técnicas de DNA recombinante, para producir vacunas muy seguras y efectivas.

El virus de la encefalitis venezolana tiene 11 subtipos, el IA, IB y IC, son epizoóticos y afectan principalmente a los caballos; también son patogénicos para el hombre. Hay cepas enzoóticas que tienen ciclos de transmisión que involucran a roedores y mosquitos del género Melanoconion. Tienen una distribución endémica por lo que un brote de esta enfermedad fuera de sus áreas endémicas, o en zonas donde no exista el vector o donde no exista enfermedad en equinos, debe ser sospechoso de una introducción del virus fuera de su ambiente natural.

Los alfavirus suelen manifestarse en un principio, como un síndrome viral que consiste en fiebre, cefalea y mialgias, con progresión al deterioro neurológico. Varían ampliamente en las secuelas neurológicas que pueden llegar a producir. En general, el síndrome encefálico se manifiesta con cefalea, fiebre, confusión, obnubilación, disfasia, convulsiones, paresia, ataxia, mioclonía y parálisis de nervios craneales.

La infección por encefalitis equina venezolana siempre es sintomática en el humano. Los pacientes desarrollan fiebre alta $\left(38 \mathrm{a} 40.5^{\circ} \mathrm{C}\right)$, escalofríos, cefalea y malestar. También son comunes la odinofagia, la fotofobia, las mialgias y los vómitos. Sólo un pequeño porcentaje desarrolla manifestaciones neurológicas $(0.5 \%$ a $4 \%)$.

Las encefalitis equina del este y del oeste son muy parecidas en su presentación. En adultos se manifiesta un pródromo febril de aproximadamente 11 días antes de las manifestaciones neurológicas. Los síntomas inician con malestar, cefalea, fiebre, náusea y vómito. Posteriormente aparecen somnolencia o delirium que pueden progresar a coma.

La encefalitis equina del este es la más severa, con altas tasas de mortalidad y secuelas neurológicas. La tasa de mortalidad se estima en 50 a $75 \%$. El 30\% de los pacientes quedan con secuelas neurológicas como: convulsiones, parálisis espástica y neuropatías craneales.

El diagnóstico específico requiere aislamiento del virus y pruebas serológicas; la detección de anticuerpos por ELISA es posible desde la segunda semana de inicio de la sintomatología.

No hay tratamiento específico y sólo se manejan síntomas como convulsiones y fiebre. ${ }^{21,22}$

\section{Viruela}

El virus de la viruela pertenece a la familia de Poxvirus. Esta enfermedad no existe ya que el último caso en el mundo ocurrió en Somalia en 1977; en México el último caso ocurrió en 1951. El hecho de que sea altamente infectante en aerosol y que es un virus relativamente estable, lo hace un buen candidato como arma biológica.

De todos los agentes infecciosos potencialmente utilizables, el virus de viruela es el más temible dado que su eficacia para transmitirse provocaría una diseminación mundial en pocas semanas.

Los síntomas se inician después de un periodo de incubación de 12 días con manifestaciones prodrómicas (2 a 4 días) caracterizadas por malestar general; posteriormente aparece el exantema, caracterizado por máculas y pápulas, que progresa uniformemente a vesículas, pústulas y costras; las lesiones son más abundantes en la cara y en las extremidades. Una característica importante es que el exantema es centrífugo y sincrónico. En la forma fulminante la muerte puede ocurrir antes de que aparezca el exantema. El contagio requiere de contacto cercano aunque puede ocurrir por vía aérea. El paciente es contagioso desde el día 3 al 6 de inicio de la fiebre, hasta que desaparecen las costras. La mortalidad es de 20 a $50 \%$.

Los pacientes se deben mantener en aislamiento de contacto hasta que desaparezcan las costras. Se 
requiere estricta cuarentena, con aislamiento respiratorio durante 17 días, para todas las personas en contacto directo con el caso índice. ${ }^{21,22}$

\section{Botulismo}

Resulta de la intoxicación por las neurotoxinas producidas por Clostridium botulinum; se han descrito siete toxinas basadas en diferencias antigénicas. Los serotipos A, B, E y F producen enfermedad en el hombre mientras que $\mathrm{C}$ y $\mathrm{D}$ casi exclusivamente producen enfermedad en animales. Es un microrganismo anaerobio, que produce esporas altamente resistentes al calor y la desecación; la ebullición estimula su crecimiento, por lo que su destrucción requiere de altas temperaturas a presión.

La forma de infección es la gastrointestinal, donde la toxina es absorbida en duodeno y yeyuno, desde donde pasa a la sangre y alcanza los nervios periféricos en la unión neuromuscular, allí previene la liberación de acetilcolina. También produce su toxicidad al ser inhalada.

El inicio de la sintomatología varía de la cantidad de toxina ingerida, pero se puede esperar desde 24 a 36 horas, hasta varíos días después de la exposición. Los síntomas incluyen parálisis craneal (bilateral) acompañada de midriasis, diplopia, ptosis, fotofobia, disartria, disfonía, disfagia. Posteriormente se presenta parálisis simétrica descendente, que puede culminar en falla respiratoria. La progresión desde el inicio de los síntomas hasta la falla respiratoria suele durar 24 horas.

El diagnóstico debe sospecharse cuando además el paciente no tiene fiebre, las manifestaciones neurológicas son simétricas, el paciente permanece conciente, el ritmo cardiaco está normal (a menos que haya hipotensión) y no presenta déficit sensorial.

El tratamiento de apoyo es fundamental, además de la administración de antitoxina (trivalente: A, B y E), se administra un vial en forma intravenosa y uno intramuscular; no son necesarias dosis subsiguientes. La alergia puede ocurrir en 9 a 20\% de los casos por lo que se recomienda prueba cutánea antes de iniciarlo, y desensibilizar si es necesario. ${ }^{20-22}$

\section{Fiebres hemorrágicas virales}

Las fiebres hemorrágicas son producidas por un diverso grupo de virus RNA que pertenecen a distintas familias. En general comparten algunas características clínicas inespecíficas que no permiten reconocerlas hasta que surge la hemorragia, como: fiebre, leucopenia, exantema, alteraciones del estado mental y diáte- sis hemorrágica. Requieren de reservorios animales ya sea roedores o artrópodos para reproducirse, por lo que no serían de primera elección para un ataque bioterrorista. Los principales agentes etiológicos de las fiebres hemorrágicas, que pueden llegar a utilizarse con fines bioterroristas, se muestran en el cuadro IV. 6,20,22,23

\section{Virus Hanta}

Los virus Hanta son de RNA e incluyen un gran número de miembros. Algunos de ellos pueden producir fiebre hemorrágica con síndrome renal. El virus se encuentra en títulos altos en las excretas de roedores por lo que la enfermedad se adquiere por la inhalación de excretas de roedor con partículas virales. En general tienen un periodo de incubación de 2 a 3 semanas, posterior al cual hay un inicio abrupto de fiebre, asociado a malestar general, cefalea, dolor lumbar, dolor abdominal, náusea y vómito. Es común que se presente hemorragia o inyección conjuntival con petequias en la conjuntiva tarsal y en el paladar. Durante esta fase es característico que se presente un exantema que desaparece con la digitopresión en cara, cuello y tórax. Esta fase febril suele durar de 3 a 7 días, posterior a la cual puede presentarse hipotensión y choque debido a manifestaciones hemorrágicas. Alrededor de $20 \%$ de los pacientes desarrollan enfermedad grave y 5 a $10 \%$ presentan choque e insuficiencia renal. El tratamiento se limita a medidas de sostén. Tienen la limitante de que se reproducen pobremente en cultivos celulares por lo que sería difícil utilizarlos como armas biológicas. ${ }^{21,22}$

\section{Cuadro IV \\ VIRUS POTENCIALES A UTILIZARSE COMO ARMAS BIOLÓGICAS}

\begin{tabular}{|c|c|c|c|}
\hline Familia & Género & Agente & Enfermedad \\
\hline Bunyaviridae & $\begin{array}{l}\mathrm{N} \text { airovirus } \\
\text { del Congo }\end{array}$ & $\begin{array}{l}\text { Fiebre hemorrágica } \\
\text { del Congo }\end{array}$ & Fiebre hemorrágica \\
\hline & Hantavirus & $\begin{array}{l}\text { Virus H antaan } \\
\text { con síndrome renal }\end{array}$ & Fiebre hemorrágica \\
\hline & Flebovirus & $\begin{array}{l}\text { Fiebre del Valle } \\
\text { del Rift }\end{array}$ & $\begin{array}{l}\text { Fiebre del Valle } \\
\text { de Rift }\end{array}$ \\
\hline Arenaviridae & Arenavirus & Virus Lassa & Fiebre Lassa \\
\hline Flaviviridae & & $\begin{array}{l}\text { Virus de la fiebre } \\
\text { amarilla }\end{array}$ & Fiebre amarilla \\
\hline Filoviridae & & $\begin{array}{l}\text { Virus Ebola } \\
\text { Virus Marburg }\end{array}$ & Ebola \\
\hline
\end{tabular}

Fuente: referencias 22 y 23 
Virus Ebola

Pertenece a la familia Filoviridae. El virus Ebola es muy virulento y produce una enfermedad grave de rápida evolución, con alta mortalidad. Recientemente el virus se ha aislado de los macacos y se cree que son el reservorio natural. Se desconoce el mecanismo de transmisión, pero una vez establecida la infección, se presentan casos en la población principalmente en personas que mantienen contacto íntimo con los enfermos y en los trabajadores de la salud. El periodo de incubación va de 5 a 10 días, posterior al cual los pacientes se presentan con un inicio súbito de fiebre, cefalea frontal severa, anorexia, malestar y mialgias. Dos a tres días después se presenta un deterioro clínico manifestado por faringitis, conjuntivitis, náusea, vómito, dolor abdominal y diarrea líquida. Cinco días después se presenta un exantema máculo-papular en tronco y posteriormente aparecen petequias, equimosis, hemorragia subconjuntival, epistaxis, hemoptisis, hematemesis y melena. Suele presentarse choque hipovolémico que progresa a la muerte. No hay tratamiento efectivo, pero se ha visto que el plasma que contiene anticuerpos contra el virus puede ofrecer alguna esperanza. Se requiere aislamiento de contacto en casos sospechosos o confirmados. . $^{21,22,25}$

\section{Fiebre amarilla}

Es producida por el virus de la fiebre amarilla que es un arbovirus del grupo B. Es endémica en Africa y Sudamérica y se transmite de persona a persona, por mosquitos, entre ellos el Aedes. El virus requiere replicarse previamente dentro del mosquito. El periodo de incubación es de 3 a 6 días y las manifestaciones clínicas inician con malestar, cefalea, dolor retrorbitario, náusea, vómito, fotofobia y bradicardia. Alrededor de $15 \%$ de los pacientes desarrollan enfermedad grave que, además de las manifestaciones previas, presenta hipotensión, ictericia, delirio y puede progresar a coma y hemorragia gastrointestinal, nasal y oral.

El tratamiento se limita a medidas de sostén ya que no hay terapia antiviral específica. A pesar de que es altamente infectante por aerosoles, el amplio uso y disponibilidad de una vacuna muy efectiva limita su uso como arma. ${ }^{21,26}$

\section{Fiebre Lassa}

Es una enfermedad muy contagiosa y virulenta. Como la mayoría de las fiebres hemorrágicas, los roedores son muy importantes para la diseminación de la enfermedad. La rata Mastomys natalensis es el reservorio. El humano contrae la enfermedad al ingerir alimentos con orina contaminada de la rata. El periodo de incubación va de 7 a 18 días. El inicio suele ser insidioso con fiebre, escalofríos, cefalea, y mialgias; posteriormente aparecen anorexia, náusea, vómitos, mialgias, dolor torácico y tos seca. A la exploración suele observarse rubefacción facial en región $V$ del cuello, faringitis muy dolorosa, con placas blanquecinas confluentes. Las manifestaciones hemorrágicas no son tan pronunciadas como en otras enfermedades de este grupo, ya que pueden limitarse a epistaxis e inyección conjuntival. La administración de plasma inmune de pacientes convalecientes produce mejoría. También la ribavirina administrada dentro de los primeros siete días de iniciado el cuadro clínico es efectiva. ${ }^{21}$

\section{Profilaxis}

Para la mayoría de estos agentes biológicos existe quimioprofilaxis que aunque no garantiza que no se presente la enfermedad, puede disminuir la severidad de las manifestaciones clínicas cuando se administra a los contactos, o ante la sospecha de manifestaciones clínicas. En el cuadro V se muestra la profilaxis recomendada ante contacto con diversos agentes.

\section{Medidas de protección en trabajadores de la salud ante armas biológicas}

Las medidas de protección en trabajadores de la salud tienen como finalidad reducir los riesgos de transmisión de pacientes con sospecha o diagnóstico de enfermedades infecciosas potencialmente transmisibles.

La importancia de estas medidas es no sólo para los trabajadores, sino para la comunidad en general, puesto que al ser el hospital un sitio de concentración de casos, se debe evitar la transmisión del hospital a la comunidad por los propios trabajadores de la salud que se infectaran. Esta situación ha sido demostrada en las epidemias del Ebola.

Estas medidas de protección han existido desde siglos pasados, y se conocen prácticamente como sistemas de aislamiento. Desde 1877 se han separado los pacientes infectados de los pacientes sin infección aparente, pero es hasta la década de los años 50 (siglo XX) cuando se establecen precauciones, de acuerdo con los diagnósticos, y que van refinándose conforme el conocimiento de la transmisión de patógenos ha aumentado, hasta las actuales que aquí describimos. ${ }^{27}$ 


\section{Cuadro V \\ Profilaxis recomendada, ante contacto CON DIVERSOS AGENTES}

\begin{tabular}{|c|c|}
\hline Agente & Quimioprofilaxis \\
\hline Bacillus anthracis & $\begin{array}{l}\text { Ciprofloxacina } 500 \mathrm{mg} \text { V0 c/12 h, por cuatro } \\
\text { semanas. }\end{array}$ \\
\hline Brucella sp & D oxiciclina y rifampicina por tres semanas \\
\hline Yersinia pestis & $\begin{array}{c}\text { Tetraciclina } 500 \text { mg/día, VO por siete días } \\
0 \\
\text { Doxiciclina } 100 \mathrm{mg} \mathrm{c} / 12 \mathrm{~h}, \mathrm{~V} 0 \text { por siete días }\end{array}$ \\
\hline Coxiella burnetii & $\begin{array}{l}\text { Tetraciclina Vo (iniciarse entre los } 8 \text { a } 12 \text { días } \\
\text { posexposición), por cinco días } \\
0 \\
\text { Doxiciclina (iniciarse entre los } 8 \text { a } 12 \text { días } \\
\text { posexposición), por cinco días }\end{array}$ \\
\hline Francisella tularensis & $\begin{array}{c}\text { Doxiciclina } 100 \mathrm{mg} \mathrm{c} / 12 \text { h,V0 por } 14 \text { días } \\
0 \\
\text { Tetraciclina } 2 \mathrm{gr} / \mathrm{día}, \mathrm{V} 0 \text { por } 14 \text { días }\end{array}$ \\
\hline Viruela virus & $\begin{array}{l}\text { Gamaglobulina vaccinia } 0.6 \mathrm{ml} / \mathrm{kg} \text { (dentro de los } \\
\text { tres días posexposición) }\end{array}$ \\
\hline
\end{tabular}

Fuente: referencia 22

\section{Mecanismos de transmisión}

Existen cuatro rutas para la transmisión de los microrganismos:

- Contacto directo: ocurre al tocar directamente al paciente sin que se tenga ningún tipo de barrera

- Contacto indirecto: sucede sin que se tenga ninguna protección cuando se tocan superficies, equipo médico o mobiliario

- Gotas: esta transmisión se da cuando se inhalan gotas mayores a cinco micras, es decir al toser, estornudar, hablar o en algún procedimiento como broncoscopías

- Aire: la transmisión por gotas ocurre cuando se aspiran gotas menores a cinco micras, que de igual manera se expulsan al toser, estornudar, hablar o en algún procedimiento invasivo. ${ }^{16,28}$

\section{Precauciones estándar}

Las precauciones estándar deben aplicarse para el cuidado de todos los pacientes dentro y fuera del hospital, sin tomar en cuenta su diagnóstico. Esta práctica tiene como objetivo reducir las posibilidades de contacto con sangre, líquidos corporales y secreciones. Éstas consisten en:
- Lavado de manos antes y después del contacto con pacientes, superficies, y después del uso de guantes

- Uso de guantes no estériles, ante la sospecha de tener contacto con sangre, líquidos o cualquier secreción, o para tener contacto con objetos contaminados

- Uso de cubreboca y lentes en procedimientos que puedan generar salpicaduras

- Uso de bata no estéril y de preferencia impermeable para proteger la piel en procedimientos que puedan generar salpicaduras o derrames

- El cuidado de la ropa: para la manipulación, transporte y proceso de la ropa usada, deberá realizarse previniendo exposición a membranas mucosas. Se deberá utilizar bolsa para su transporte y en el caso de ropa con sangre o secreciones utilizar guantes

- Uso de recolectores: para depositar objetos punzocortantes; asimismo nunca rencapuchar, doblar, quitar, romper o manipular objetos punzocortantes

- Para la limpieza del cuarto del paciente, la sala del quirófano o la de necropsia, hacerla únicamente con agua, jabón y posteriormente agua con hipoclorito de sodio al $0.5 \%$

- En caso de derrames de sangre o líquidos corporales, desinfectar con hipoclorito de sodio al 5\% directamente sobre el derrame. ${ }^{16,28}$

\section{Precauciones para contacto}

Además de utilizar las precauciones estándar, deberán utilizarse las de contacto en pacientes conocidos o con sospecha de infección por microorganismos transmitidos por contacto directo o indirecto.

- De preferencia un cuarto aislado

- Guantes no estériles al entrar al cuarto, durante el contacto con el paciente y deberán retirarse al salir del cuarto

- El traslado del paciente debe realizarse lo menos posible

- Ejemplos: Estafilococo aureus, Enterococo sp, heridas infectadas, úlceras por presión.

En el cuadro VI se describen las precauciones que se recominenda tomar ante organismos utilizados como armas biológicas. ${ }^{16,28}$

\section{Precauciones para transmisión por gotas}

Además de las precauciones estándar, utilizar estas precauciones en pacientes con padecimientos transmitidos por gotas: 


\begin{tabular}{|c|c|c|c|c|c|c|}
\hline \multicolumn{7}{|c|}{$\begin{array}{c}\text { Cuadro VI } \\
\text { Precauciones en agentes como armas biológicas }\end{array}$} \\
\hline Enfermedad & $\begin{array}{l}\text { Transmisión de } \\
\text { persona a persona }\end{array}$ & $\begin{array}{l}\text { Forma de } \\
\text { transmisión }\end{array}$ & $\begin{array}{l}\text { Precaución } \\
\text { estándar }\end{array}$ & $\begin{array}{c}\text { Otras } \\
\text { precauciones }\end{array}$ & $\begin{array}{l}\text { Necropsias/ } \\
\text { incineración }\end{array}$ & $\begin{array}{l}\text { Manejo del } \\
\text { equipo }\end{array}$ \\
\hline $\begin{array}{l}\text { Carbunco } \\
\text { (Antrax) }\end{array}$ & No & $\begin{array}{l}\text { Vía aérea } \\
\text { (inhalación de esporas) }\end{array}$ & Sí & $\begin{array}{l}\text { Con pacientes, ninguna. } \\
\text { Precauciones para vía aérea, } \\
\text { utilizar máscara de } 100 \% \text { de } \\
\text { efectividad en el caso de } \\
\text { sospecha de inhalación de polvos }\end{array}$ & Sí & $\begin{array}{l}\text { Desinfección con hipoclorito } \\
\text { de sodio al } 5 \% \\
\text { en caso de derrames }\end{array}$ \\
\hline $\begin{array}{l}\text { Botulismo } \\
\text { (Clostridium botulinum) }\end{array}$ & No & Alimentos contaminados & Sí & Ninguna & No & Limpieza con agua y jabón \\
\hline Peste (Yersinia pestis) & Alta & Gotas & Sí & $\begin{array}{l}\text { Gotas } \\
\text { Respirador con filtro del } \\
95 \% \text { de efectividad }\end{array}$ & Sí & $\begin{array}{l}\text { Desinfección con hipoclorito } \\
\text { de sodio al } 0.5 \% \text {; en caso de } \\
\text { derrames hipoclorito de } \\
\text { sodio al } 5 \%\end{array}$ \\
\hline Viruela & Alta & Vía aérea & Sí & $\begin{array}{l}\text { Vía aérea } \\
\text { Espirador con filtro del } 95 \% \\
\text { de efectividad }\end{array}$ & Sí & $\begin{array}{l}\text { Desinfección con hipoclorito } \\
\text { de sodio al } 0.5 \% \text {; en caso de } \\
\text { derrames hipoclorito de } \\
\text { sodio al } 5 \% \text {. }\end{array}$ \\
\hline Tularemia & No & $\begin{array}{l}\text { Aerosoles en la manipulación } \\
\text { de tejidos }\end{array}$ & n Sí & N inguna & No & \\
\hline $\begin{array}{l}\text { Fiebres hemo rágicas } \\
\text { virales }\end{array}$ & $\begin{array}{l}\text { Alta a } \\
\text { moderada }\end{array}$ & $\begin{array}{l}\text { Sangre, secreciones, } \\
\text { órganos }\end{array}$ & Sí & $\begin{array}{l}\text { Precauciones de contacto, } \\
\text { guantes, bata, mascarilla }\end{array}$ & & \\
\hline
\end{tabular}

- Cuarto aislado

- Cubreboca con filtro de 95\% de efectividad cuando se encuentra a menos de $1 \mathrm{~m}$ de distancia del paciente

- Ejemplos: enfermedad invasiva por Haemophilus influenzae, Neisseria meningitidis, difteria, tos ferina, parotiditis, rubéola, influenza, parvovirus.

\section{Precauciones para vía aérea}

Además de las precauciones estándar utilice estas precauciones en pacientes con padecimientos transmitidos por vía aérea:

- Cuarto con presión negativa

- Cubreboca con filtros de 95 \% de efectividad

- Evitar el traslado del paciente

- Ejemplos: tuberculosis pulmonar, varicela, sarampión

\section{Conclusiones}

México comparte una extensa frontera con los EUA y, además de la extensión, su tránsito es muy intenso. Ante las precauciones establecidas en los EUA una posibilidad obvia es intentar un ataque a través de nuestro territorio, lo que nos convierte en el segundo blanco potencial. Por esto, aun considerando que un ataque con estas características es muy remoto, es necesario establecer una organización mínima que permita la identificación más temprana posible, el diagnóstico correcto y las acciones preventivas inmediatas.

Si bien nuestro sistema de vigilancia se ha fortalecido paulatinamente, es claro que tiene limitaciones entre las que destacan una grave falta de recursos para diagnóstico microbiológico y también de apoyo forense, particularmente para el diagnóstico de agentes infecciosos no habituales. Simultáneamente, existe escasa participación de los clínicos en actividades de reporte epidemiológico, lo que puede implicar un retraso muy grave en el caso de situaciones de urgencia epidemiológica.

El cambiante panorama epidemiológico requiere de una infraestructura suficiente para establecer diagnósticos de enfermedades emergentes o insólitas, como sería el caso de una agresión bioterrorista. La tecnología permite ahora establecer identificaciones, en pocas horas, de múltiples agentes infecciosos, por análisis de ácidos nucleicos y debería ser accesible en laboratorios de referencia localizados estratégicamente $y$, si- 
multáneamente, mejorar las capacidades de los actuales.

Todas las acciones requieren de presupuestos suficientes para ampliar plazas, equipos e instalaciones, por lo que deberán existir asignaciones particulares y no esperar que con lo ya asignado se realicen otras actividades. La situación es potencialmente de extrema gravedad y así deberá considerarse al cuantificar la inversión.

\section{Referencias}

1. Jernigan JA, Stephens DS, A shrord DA, 0 menaca C, Topiel MS, Galbraith M. Bioterrorism-related inhalational Anthrax:The first 10 cases reported in the U nited States. Emerg Infect D is 2001;6(7):1-26.

2.Update: Investigation of bioterrorism-related Anthrax and interim guidelines for clinical evaluation of persons with possibleAnthrax. MMW R. Morb Mortal W kly Rep 2001 N ovember 2;50(43):941-948.

3.Tucker J. Historical trends related to bioterrorism:An empirical analisis. Emerg Infect D is 1999;5(4):498-504.

4. Meselson M, Guillemin J,H ugh-Jones M, Lagmuir A, Popova llona, Shelokov A et al. The Sverdlovsk anthrax outbreak of 1979. Science 1994 N ovember 18;34(266):1202-1207.

5. Zilinskas RA. Iraq's biological weapons. JAMA 1997;278(5):418-424.

6. Cole LA.The specter of biological weapons. Sci Am 1996;275(6):30-35.

7. KaufmannAF, M eltzler MI,Schmid G P.The economic impact of a bioterrorist attack. Emerg Infect $D$ is 1997;3:83-84.

8.Tucker JB. National health and medical services response to incidents of chemical and biological terrorism. JAMA 1997;278(5):362-368.

9. Geiger HJ. Terrorism, biological weapons, and bonanzas: Assessing the real threat to public health. Am J Public Health 2001;91(5):708-709.

10. Spencer RC, Lightfoot N F. Preparedness and response to bioterrorism.J Infect 2001;43:104-110.

11. Fidler D P.The malevolent use of microbes and the rule of law: Legal challenges presented by bioterrorism. Confronting Biological Weapons 2001;33:686-689.

12. Eitzen EM Jr. Education is the key to defense against bioterrorism.Ann Emerg Med 1999;34:221-223.
13. Keim M.Principles for emergency response to bioterrorism.Ann Emerg Med 1999;34(2):177-182.

14. W aeckerle JF. Disaster planning and response. $\mathrm{N}$ Engl J Med 1991;324:815-821.

15.W aeckerle JF. D omestic preparedness for events involving weapons of mass destruction. JAMA 2000;283(2):252-254.

16. Secretaría de Salud. Subsecretaría de Prevención y Protección de la Salud. Dirección $G$ eneral de Epidemiología. Lineamientos para la vigilancia, prevención, control, toma y manejo de muestras de laboratorio de enfermedades asociadas a riesgos biológicos. México, D.F.: SSA, 2001.

17. Jortani $S A, Z$ inder JW,Valdes $R$. The role of the clinical laboratory in managing chemical or biological terrorism. C lin C hem 2000;46:1883-1893. 18. W illiams JL, Sheesley D. Response to bioterrorism directed against animals. Ann N Y Acad Sci 2000;916:117-120.

19. Pesik N , Keim ME, Iserson KV.Terrorism and the ethics of emergency medical care.Ann Emerg Med 2001;37:642-646.

20. Balk SJ,A bramson JS, Baker CJ, Peter G. Chemical-biological terrorism and its impact on children:A subject review. Pediatrics 2000;105(3).

21. Mandell. Principles and practice of infectious diseases. 5a. edición, Londres (UK): C hurchill Livingstone, Inc, 2000.

22. Franz DR, Jahr ling PB, Friedlander AM, McC lain DJ, Hoover D L, Bryne $W R$ et al. Clinical recognition and management of patients exposed to biological warfare agents. JAMA 1997 August 6;278(5):399-411.

23. Biological and chemical terrorism: Strategic plan for preparedness and response. Recommendations of the CDC Strategic Planning W orkgroup. MMW R Morb Mortal W kly Rep 2000;49(RR-4): 1-13.

24. Update: Investigation of bioter rorism-related Anthrax and interim guidelines for exposure management and antimicrobial therapy. MMW R Morb Mortal W kly Rep 20010 ctober 26;50(42):909-919.

25. Gradon J.An outbreak of Ebola virus: Lessons for everyday activities in the intensive care unit. Crit C are Med. 2000;28(1):284-285.

26. Roberson SE, Hull BP,Tomor LO, Bele 0 , LeD uc JW, Esteves K.Yellow fever:A decade of reemergence. JA MA 19960 ct 9;276(14):1157-1162.

27. Klietmann W F. Bioterrorism: Implications for the clinical microbiologist. Clin Microbiol Rev 2001;14(2):364-381.

28. Kortepeter M, Christopher G, CieslakT, Culpepper R, D arling R, Pavlin J et al. USAMRIID'S Medical management of biological casualties handbook. 4a. edición. Fort D etrick (MD):USArmy Medical Research Institute of Infectious Diseases (USA-MRIID), 2001.

29. Spencer RC, Lightfoot N F. Preparedness and response to bioterrorism.J Infet 2001;43:104-110. 